\title{
Crise do capital e impacto da covid-19 na vida dos trabalhadores: desigualdades socioterritoriais na periferia e em regiões do Brasil
}

Joana Valente Santana'

Benedito de Jesus Pinheiro Ferreira²

\section{Resumo}

Este artigo, a partir de levantamento bibliográfico e documental, analisa os impactos da atual crise capitalista, agravados pela evolução da pandemia da Covid-19 na vida dos trabalhadores, diante das desigualdades socioterritoriais na periferia urbana e regionais, especialmente nas regiões Norte e Nordeste. A população brasileira sofre da total incapacidade e desinteresse do Governo Federal em enfrentar os problemas da pandemia, o qual promove um intenso ataque aos direitos trabalhistas e ao patrimônio público para garantir os ganhos de frações de classe dominante parasitárias, particularmente as ligadas ao capital financeiro. Cabe reconhecer as iniciativas de organização solidária da própria classe trabalhadora no enfrentamento da pandemia.

\section{Palavras-chave}

Crise do capital; Covid-19; Desigualdade socioterritorial; Periferia urbana; Regiões Norte e Nordeste.

Capital crisis and impact of covid-19 on workers' lives: socio-territorial inequalities in the periphery and regions of Brazil

\begin{abstract}
This article, based on a bibliographic and documentary survey, analyzes the impacts of the current capitalist crisis, aggravated by the evolution of the Covid-19 pandemic on the lives of workers, given the socio-territorial inequalities in the urban and regional peripheries, especially in the North and Northeast regions. The Brazilian population suffers from the total incapacity and disinterest of the federal government to face the problems of the pandemic, which promotes an intense attack on labor rights and public assets, aiming to guarantee the gains of parasitic ruling class fractions, particularly those linked to financial capital. It is worth recognizing the initiatives of solidarity organization of the working class itself in facing the pandemic.
\end{abstract}




\section{Keywords}

Crisis of capital; Covid-19; Socioterritorial inequality; Urban periphery; North and Northeast regions.

Artigo recebido em junho 2020

Artigo aprovado em agosto de 2020

Esses milhares de indivíduos, de todos os lugares e de todas as classes, que se apressam e se empurram, não serão todos eles seres humanos com as mesmas qualidades e capacidades e com o mesmo desejo de serem felizes?

Friedrich Engels (2008, p. 68)

\section{Introdução}

No momento da escrita deste artigo (junho de 2020) torna-se impossível, para analisar a "questão social" e suas expressões, desconsiderar a pandemia global da Covid-19 que nos últimos meses determinou mudanças comportamentais a bilhões de indivíduos e tem trazido enorme sofrimento, na forma de adoecimento, perdas de entes queridos e danos psicológicos à sociedade. A complexidade desses fenômenos é acentuada na medida em que esses se dão já no contexto de uma profunda crise econômica, com impactos de grande monta sobre a classe trabalhadora; crise que não se originou, mas se acentuou drasticamente com a pandemia. No caso particular do Brasil, uma crise política e institucional, com fortes incertezas a respeito da estabilidade da democracia formal, agrava o quadro. Um governo protofascista, com traços anticientificistas e marcado por exacerbados ataques aos direitos trabalhistas e serviços públicos dirigidos à classe trabalhadora, em um grave momento como este, nega à sociedade qualquer plano consistente para enfrentar a pandemia, em especial sua marca mais drástica: as perdas de vidas.

Um desafio para os estudiosos de diferentes áreas, identificados com os interesses coletivos e, em especial, da classe trabalhadora, é 
compreender adequadamente esses inúmeros fenômenos, para viabilizar seu enfrentamento. Assim, segundo o método do materialismo histórico e dialético, impõe-se a busca, para além da imediaticidade do tempo presente, das determinações históricas desses fenômenos, considerando-se as suas articulações com a totalidade da sociedade burguesa. Trata-se também de realizar uma cuidadosa reflexão sobre as mediações possíveis, por parte da classe trabalhadora, para o enfrentamento da luta de classes, ora tão acentuada.

A proposta deste artigo, com base em levantamento bibliográfico e documental, é analisar os impactos que essa conjugação de crise econômica e pandemia global estão levando à vida dos trabalhadores empobrecidos, em especial os que vivem nas periferias urbanas do país e nas regiões de maiores desigualdades socioeconômicas, notadamente nas regiões Norte e Nordeste do país. Sua estrutura é a seguinte: inicialmente, será abordado o caráter da crise econômica global que já se anunciava e se manifestava antes da pandemia; em um segundo momento, será analisada a posição internacional do Brasil em termos de sua (in)capacidade de enfrentamento da pandemia; na seção seguinte tratar-se-á do impacto da pandemia da covid-19 na vida dos trabalhadores, considerando-se as desigualdades socioterritoriais no âmbito das periferias urbanas e das regiões no Brasil; finalmente, virão as considerações finais.

\section{Crise econômica global e suas repercussões na periferia do capitalismo}

Em seus estudos sobre a gênese, leis fundamentais e tendências da produção capitalista, Marx e Engels, quando da elaboração do Manifesto Comunista, já tinham consciência da importância das crises periódicas do capital e da necessidade da sua correta apreensão. Apontavam o caráter paradoxal dessas crises, por expressarem "civilização em excesso, meios de subsistência em excesso" (MARX; ENGELS, 2010, p. 45), algo inconcebível nos modos de produção anteriores. 
As forças produtivas de que dispõe [a sociedade] não mais favorecem o desenvolvimento das relações burguesas de propriedade; pelo contrário, tornam-se poderosas demais para estas condições, passam a ser tolhidas por elas; e assim que se libertam desses entraves, lançam na desordem a sociedade inteira e ameaçam a existência da propriedade burguesa (MARX; ENCELS, 2010, p. 45).

Revelava-se também o fato de que as tentativas de solução para crises apenas as remetiam a um futuro, onde apareceriam de forma mais aguda, visto que parte das supostas soluções não estariam mais disponíveis ou, ainda, que novos elementos se somariam aos das crises anteriores. A busca de soluções se orientava:

De um lado, pela destruição violenta de grande quantidade de forças produtivas; de outro lado, pela conquista de novos mercados e pela exploração mais intensa dos antigos. A que leva isso? Ao preparo de crises mais extensas e mais destruidoras e à diminuição dos meios de evitá-las (MARX; ENGELS, 2010, p. 45).

São fundamentais para se compreender a dinâmica das crises no capitalismo os fenômenos da concentração e centralização dos meios de produção, tanto consequência, quanto elementos formadores de novas crises. No citado manifesto de 1848 essa tendência à concentração já estava apreendida pelos estudiosos, a ser mais bem decifrada nos estudos futuros: "A burguesia suprime cada vez mais a dispersão dos meios de produção, da propriedade e da população. Aglomerou as populações, centralizou os meios de produção e concentrou a propriedade em poucas mãos." (MARX; ENGELS, 2010, p. 44). Após os monumentais estudos de Marx (com intensa colaboração de Engels), essas tendências seriam mais bem compreendidas. No Volume II do Livro 1 de O Capital, tem-se uma maior riqueza categorial, com a necessária distinção entre concentração e centralização do capital ${ }^{3}$. 
A validade dessas categorias, em termos ontológicos e explicativos da dinâmica do capital tem sido verificada historicamente, decorridos mais de século e meio da sua apreensão por Marx e Engels ${ }^{4}$. Notadamente, os estudos de Lenin, no início do Século $X X$, detectam o acelerado processo de concentração e centralização, no clássico Imperialismo, estágio superior do capitalismo (LENIN, 2012) ${ }^{5}$. O Século XX será marcado pela formação de monopólios e cartéis, e esse novo regime de acumulação vincula-se a um padrão de crises onde problemas recorrentes de superprodução se entrelaçam com formação de bolhas especulativas de mercados imobiliários e de ações, quebras de bolsas, antecedidas de euforia e ganhos. O desenvolvimento do capitalismo estará profundamente ligado à eclosão da "Era de Catástrofe" (HOBSBAWN, 1995), de 1914 até o pós-Segunda Guerra Mundial. Como fruto das profundas contradições, destaca-se a severa crise que se seguiu à célebre quebra dos mercados de ações em 1929, e que "só se resolveu por completo nos anos 1950, depois que o mundo passou pela depressão dos anos 1930 e pela guerra mundial dos anos 1940". (HARVEY, 2016, p. 10). Para além dos grandes números da economia, fortes prejuízos atingem a classe trabalhadora, em especial o desemprego e a crescente desigualdade de riqueza e renda.

As políticas keynesianas enfrentaram esse período de crises com promoção de demanda em diversas modalidades, com destaque para o fortalecimento da indústria bélica. A gestão da demanda, com forte investimento estatal em infraestrutura, geração de empregos e oferta de serviços públicos, foi elemento decisivo para o advento da "Era de Ouro", conforme Hobsbawn (1995), dando-se um "extraordinário período de crescimento e transformação social" (p. 15), embora não isento de contradições, período que parecia ter deixado as crises para trás. Contudo, tal ilusão resistiu apenas por três décadas e uma nova crise eclodiu a partir dos anos 1970, traduzindo o esgotamento das políticas keynesianas, com a "queda generalizada das taxas de lucros com a produção” (COMES, 2015, p. 
16). Na medida da crescente dificuldade de realização do capital na esfera produtiva, buscou-se o campo da especulação.

As finanças públicas da maioria dos países, gradativamente, foram capturadas pela lógica da securitização do endividamento externo. Criava-se, desse modo, um círculo vicioso de especulação, alimentado de forma fictícia pelo endividamento das diversas nações do planeta e pelas mais variadas formas de emissão de títulos secundários e derivativos, afastando cada vez mais os preços dos papeis de qualquer lastro na produção de riquezas materiais. (COMES, 2015, p. 16, itálico no original).

Dá-se a transição para um novo regime de acumulação com dominância da valorização fınanceira, que marcará o capitalismo a partir da década de 1980, com as características: "baixo crescimento do produto; redução de salários e desemprego em boa parte dos países; enorme crescimento do valor dos ativos financeiros; conjuntura instável entrecortada por sobressaltos monetários e financeiros com alto poder de contágio entre os países" (PAULANI, 2009, p. 26).

Um elemento central de análise é que para as crises que ocorrem nesse novo contexto, como a de 2008 e a atual, faltam alternativas dentro da ordem do capital, uma vez que muitos dos mecanismos colocados em marcha para mitigar as crises do passado tornam-se cada vez mais limitados, conforme destaca Herrera (2015), referindo-se à crise iniciada em 2008:

A crise atual é mundializada, global, sistêmica; ultrapassa todas as crises internacionais do passado, em 1857, em 1907-1908, e mais ainda em 1929 e na década de 1930. O que entender então, hoje, por 'crise sistêmica'? Significa dizer que o sistema não traz e, para nós, não trará mais soluções internas à dinâmica contraditória que ele mesmo produz. (HERRERA, 2015, p. 11, itálico no original).

Harvey oferece uma aguda síntese do impasse acerca das (im) possibilidades de soluções para a crise sistêmica, dos desgastados 
remédios neoliberais, e da concentração de riqueza e de poder, elevada ao nível do paroxismo.

Em termos gerais, o mundo está polarizado entre a continuação ou até o aprofundamento das soluções neoliberais, baseadas na oferta [supply-side] e monetaristas, enfatizando a austeridade como remédio apropriado para curar nossos males (caso da Europa e dos Estados Unidos), e a retomada de uma versão em geral diluída de uma expansão keynesiana baseada na demanda e financiada pela dívida (como na China), ignorando a ênfase de Keynes na redistribuição de renda para as classes mais baixas como um de seus componentes-chave. Não importa qual política é seguida: o resultado é o favorecimento do clube de bilionários que constitui hoje uma plutocracia cada vez mais poderosa. (...) Em contrapartida, o bem-estar das massas estagna, na melhor das hipóteses, ou, mais provavelmente, sofre uma degradação crescente, se não catastrófıca (como na Grécia e na Espanha). (HARVEY, 2016, p. 10-11).

Com a atual pandemia global, a crise do capital, que já expressava por si a barbárie do sistema capitalista quanto à vida dos trabalhadores, se agrava fortemente. Harvey (2020) discute os efeitos da pandemia sobre a crise do capital e sobre a vida dos trabalhadores e reafirma a incapacidade do neoliberalismo em dar soluções tanto à crise do capital quanto à crise sanitária em curso.

As autoridades públicas e os sistemas de saúde foram apanhados em quase todos os lugares com falta de funcionários. Quarenta anos de neoliberalismo na América do Norte e do Sul e na Europa tinham deixado o público totalmente exposto e mal preparado para enfrentar uma crise de saúde pública deste tipo, apesar dos riscos anteriores da SARS e do Ebola terem fornecido abundantes avisos, bem como lições convincentes sobre o que seria necessário fazer (HARVEY, 2020, p. 17).

Dentre os inúmeros efeitos da crise econômica e sanitária, os mais perversos ocorrem, sem dúvida, sobre a vida dos trabalhado- 
res. Harvey (2020) afirma que quanto mais durar a pandemia, mais desvalorizada será a força de trabalho: "os níveis de desemprego subirão, seguramente, para níveis comparáveis aos da década de 1930, na ausência de intervenções estatais maciças que terão de ir contra o neoliberalismo" (p. 22).

\section{Impactos da covid-19: Brasil em relação ao mundo}

O fato de o Brasil ter tido as primeiras ocorrências da Covid-19 vários meses depois de outros países representou uma potencial vantagem. Alguns estudos, em março/2020 apontavam elementos que poderiam guiar ações de contenção da disseminação da pandemia e, portanto, minimizar seus prejuízos. O estudo feito por Coelho et al (2020), por exemplo, destacava os vínculos entre o tráfego aéreo nacional e os deslocamentos no interior dos estados, e o risco de surtos de infecção. Um destaque seriam as conexões aéreas de várias regiões com as cidades do Rio de Janeiro e de São Paulo, primeiras a terem transmissão comunitária do vírus.

Tais aspectos exigiriam uma articulação nacional, envolvendo as três esferas governativas, e sob uma coordenação nacional, incluindo como elemento decisivo, conforme o exemplo internacional, medidas de restrição de mobilidade de pessoas, como o isolamento e o distanciamento social. No Brasil, isso tem ocorrido de forma muito problemática. O Governo Federal, em especial o Presidente da República, Jair Bolsonaro, ao contrário, tomou inúmeras atitudes em sentido contrário: minimizou sistematicamente os prejuízos da doença, insistiu na defesa de medicamentos que seriam supostas panaceias na sua cura, usou de ironia e sarcasmo, assumiu atitudes pessoais de incentivar e participar de aglomerações sem as proteções pessoais adequadas; enfim, tem feito o oposto do que seria necessário a quem deveria liderar o enfrentamento pandêmico. Houve inúmeros conflitos deste mandatário com a maioria dos governadores e até mesmo com seus próprios ministros da saúde, o que resultou em diversas trocas de ti- 
tulares da pasta, até se configurar a singular situação do Brasil não ter, quando da escrita deste artigo, um ministro da saúde; e isso em um momento de enfrentamento de uma grave pandemia.

Além do deficiente enfrentamento por parte do governo federal, muitos governos estaduais, embora em muitos casos se contrapondo a posições presidenciais, vem cedendo a pressões para colocar em curso o afrouxamento do distanciamento social, como a abertura de atividades comerciais, o que tem levado a ocorrências de signifıcativas aglomerações, colocando-se em risco um efetivo decréscimo da curva pandêmica.

Todos esses problemas de governança se entrelaçam a efetivas dificuldades ou impossibilidade de um amplo segmento da classe trabalhadora, submetido a crescente precarização (subemprego, uberização), de realizar um isolamento adequado, seja pela necessidade de garantir, dia a dia, o sustento familiar, assim como pela falta de condições domiciliares para adotar medidas adequadas de higiene, distanciamento de familiares eventualmente com sintomas, etc. Outro fator-chave a dificultar o enfrentamento da pandemia é a crescente degradação do Sistema Único de Saúde (SUS), penalizado, como diversos outros setores das políticas sociais, pelo subfinanciamento crônico, agravado drasticamente pela Emenda Constitucional 95/2016, que estabelece um teto de gastos para as despesas primárias. Se este é um problema nacional, ele é mais grave nas regiões Norte e Nordeste, regiões que historicamente apresentam índices inferiores de desenvolvimento humano e alta desigualdade.

Esses fatores colocam o Brasil nas piores posições nos indicadores: total de casos, de óbitos, casos por 100 mil habitantes etc. $\mathrm{Na}$ comparação com os demais países dos chamados BRICS ${ }^{6}$ (Gráfico 1), o Brasil ocupa destacadamente uma posição mais desfavorável. Tratando-se de dados oficiais, e que se tem apontado alto grau de subnotificação em todos os países, são dados que precisam ser vistos com cuidado. Mas ainda assim, são números extremamente ne- 
gativos e parecem, com alta probabilidade, refletir as deficientes políticas públicas de combate à doença.

\section{Gráfico 1 - BRICS*: óbitos por 100 mil habitantes no $106^{\circ}$ dia de pandemia}

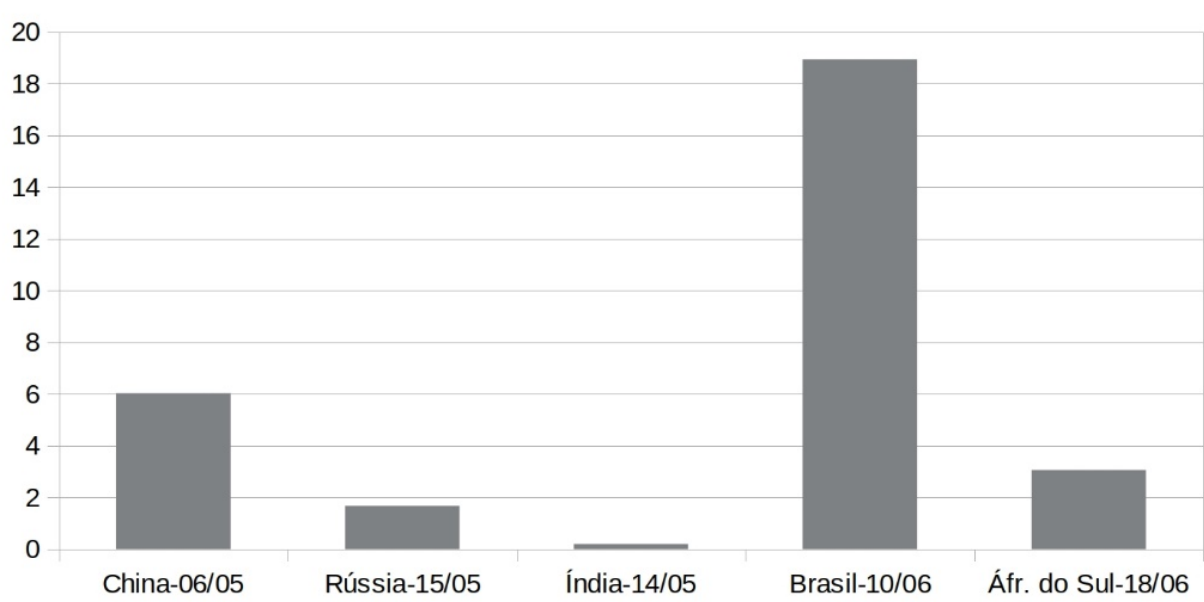

Fonte: elaboração pelos autores a partir de dados da Universidade Johns Hopkins (2020).

Na comparação com os países da América do Sul, a posição do Brasil só se mostra ligeiramente mais favorável que a dos dois países com pior situação, Equador e Peru. Tais dados comparativos revelam grandes disparidades acerca das condições de enfrentamento da pandemia, frente à riqueza produzida nessas sociedades. Dentre os países que encabeçam o índice PIB per capita em dólares estadunidenses, Chile (24.600), Uruguai (22.400) e Argentina (20.9000)7 é nítida a desvantagem do Chile, um país notório pela aplicação já na década de 1980 das políticas neoliberais e pela inexistência de um sistema de saúde gratuito e universal (DE LA FUENTE, 2020). Ressalte-se que o número de óbitos frente à população é influenciado pela propagação da doença, mas também pelo grau de disponibilidade de um serviço público de saúde, que em muitos casos entrou em colapso pelos seus limites e pelo próprio adoecimento dos profissionais de saúde, muitas vezes pelas condições de trabalho inadequa- 
das e relações trabalhistas precárias. O Brasil, que vem em $4^{\circ}$ lugar no aspecto de riqueza per capita (US\$15.600), mas igualmente com histórica desigualdade, e várias décadas de ataque ao financiamento do SUS, encontra-se em condição pior que países onde esse mesmo indicador é bastante inferior, por exemplo, Paraguai (US\$12.800), Venezuela (US\$12.500) e Guiana (US\$ 8.100).

\section{Gráfico 2 - América do Sul: óbitos por 100 mil habitantes no $100^{\circ}$ dia de pandemia}

\section{Gráfico 2 - América do Sul: Óbitos por 100 mil habitantes no $100^{\circ}$ dia de pandemia}

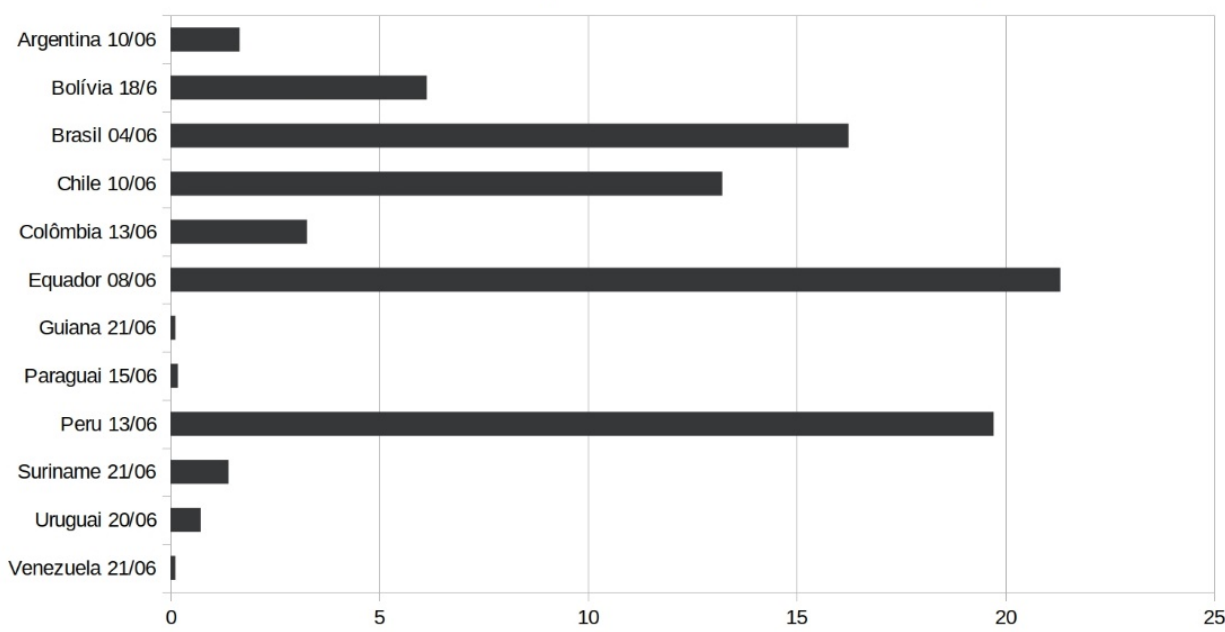

Fonte: elaboração pelos autores a partir de dados da Universidade Johns Hopkins (2020).

No indicador casos por 100 mil habitantes, dentre os países mais populosos, o Brasil, levando-se em conta o número de dias decorridos do primeiro caso, ultrapassou os Estados Unidos no $108^{\circ}$ dia de pandemia e assumiu a liderança após ultrapassar a Espanha, no dia 116 (26/05/2020) com 509,659 casos por 100 mil habitantes (UNIVERSIDADE JOHNS HOPKINS, 2020). Todos esses indicadores convergem para uma compreensão da deplorável condição que a população brasileira vive, ligada à desastrosa política de enfrentamento da pandemia global. 


\section{Desigualdades socioterritoriais na expansão da Covid-19 no Brasil: periferia urbana e regiões Norte e Nordeste}

A pandemia exacerbou a gigantesca desigualdade de classe, racial e de gênero, com incidência geracional, pelo número expressivo de mortes de idosos, e demonstrou a completa desproteção social dos trabalhadores. No caso do Brasil, soma-se a isso a segregação sócio-territorial nas cidades e a desigualdade entre as regiões do país, com impacto sobre a vida dos moradores de pequenas cidades, povos e comunidades tradicionais, especialmente territorializados nas regiões Norte e Nordeste.

A história da produção social do espaço urbano no Brasil é a história do conflito de classes e de disputa pela ocupação desse espaço. Desde o início do século XX quando o país adentra no processo tardio de industrialização e vai avançando no processo de urbanização, a classe trabalhadora - libertada apenas oficialmente da escravidão - foi ocupando os piores lugares da cidade (os mais distantes do centro e os inseridos na malha urbana), em geral mal servidos de infraestrutura básica, como água, esgoto sanitário, pavimentação, energia elétrica, coleta de lixo.

Os estudos sobre a relação entre a desigualdade socioeconômica e as condições de moradia no Brasil, demonstram os graves problemas de inadequação habitacional ${ }^{8}$, com destaque para a carência de infraestrutura.

Com base na Pesquisa Nacional por Amostra de Domicílios Contínua/ PNAD Contínua, o IBCE (2019) demonstrou a relação entre a "pobreza monetária e precariedades e vulnerabilidades nas condições de moradia" (p. 62). Para tanto, comparou a proporção da população residindo em domicílios com inadequações, total e com rendimento domiciliar per capita inferior a US\$ 5,50 PPC ${ }^{9}$ diários, segundo o tipo de inadequação, para o ano de 2018. Em todas as inadequações comparadas, os piores indices foram identificados entre as pessoas com menor rendimento.

Dentre as inadequações por carência de infraestrutura, o Gráfico 3 demonstra que a população com rendimento domiciliar per capita 
inferior a US\$ 5,50 PPC por dia tem os piores índices de serviço de coleta de lixo, abastecimento de água por rede geral e ausência de esgotamento sanitário por rede coletora ou pluvial, sendo que a dificuldade de acesso ao esgotamento sanitário entre essa população é bastante elevada, alcançando o expressivo número de 56,2\% (IBCE, 2019).

Gráfico 3 - Proporção da população residindo em domicílios com ausência de serviços de saneamento, total e com rendimento domiciliar per capita inferior a US\$ 5,50 PPC diários, segundo o tipo de serviço - Brasil - 2018

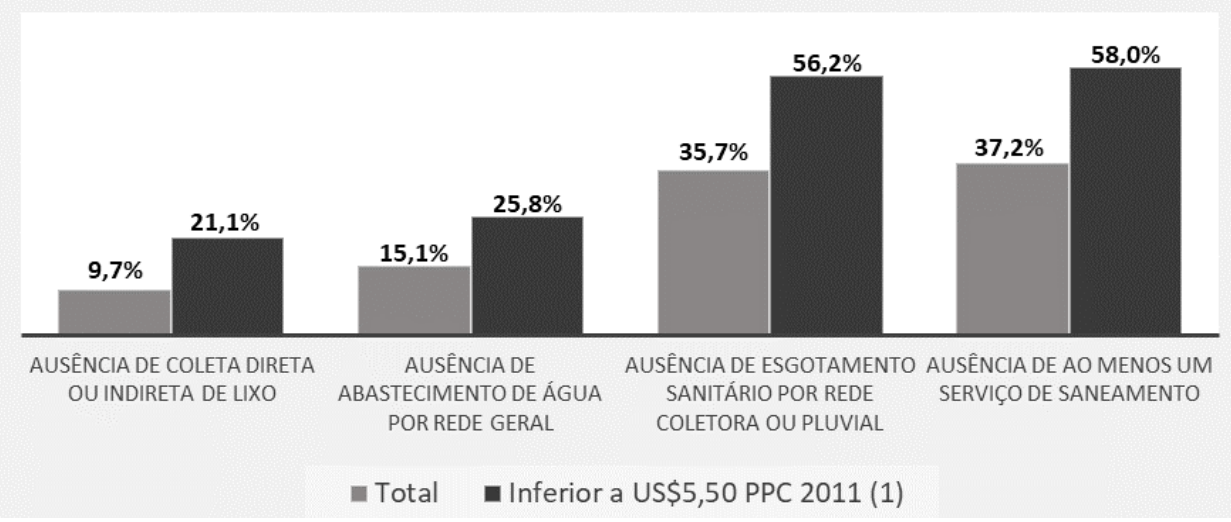

Fonte: IBGE, Pesquisa Nacional por Amostra de Domicílios Contínua 2018, apud: IBGE, 2019, p. 64. Notas: 1. Dados consolidados de primeiras entrevistas.

2. Rendimentos deflacionados para reais médios de 2018.

Com o avanço da pandemia da Covid-19, a Organização Mundial de Saúde/OMS recomenda o isolamento social como forma de contenção da propagação do vírus; orienta, portanto, que sejam evitadas aglomerações. Entretanto, diante dos dados apresentados, que revelam carência de infraestrutura no Brasil, refletindo as reais condições de vida da população brasileira, questiona-se: em que lugar o trabaIhador se protege na pandemia e quais as condições socioeconômicas e de moradia que permitam o isolamento social?

Para os trabalhadores pobres, os riscos são iminentes e maiores porque eles precisam imperiosamente vender a sua força de trabalho, mesmo correndo riscos. Como afirma Lara (2020, p. 57) muitos tra- 
balhadores "receberam a própria morte como pagamento pelas suas jornadas de trabalho, exemplo disso são os profissionais de saúde."

Se os trabalhadores ficam em casa, falta-lhes renda, e, assim, não conseguem suprir o mínimo de sobrevivência (alimento, aluguel, tarifas de água, luz e gás, medicamentos etc.).

Provavelmente, a locomoção ao trabalho em veículos lotados seja uma das maiores causas de contaminação da doença. Mas se o risco maior pode estar no deslocamento, a permanência em casa também traz risco de contaminação, considerando-se as precárias condições de moradia, especialmente nas periferias das cidades, onde a aglomeração é um elemento constituinte da lógica de espaço urbano capitalista. As casas são próximas umas das outras, os cômodos são insuficientes, e o saneamento básico, conforme os dados do IBCE (2019), é uma tragédia urbana.

Engels (2008) já denunciava as condições de vida e trabalho da classe trabalhadora no período da revolução industrial, revelando a "guerra social” empreendida pelo capital sobre o trabalho: aglomeração das moradias, baixos salários, fome, precárias condições de saneamento. “Morrem de fome, é certo, indivíduos isolados, mas que segurança tem o operário de que amanhã a mesma sorte não o espera? Quem pode garantir-lhe que não perderá o emprego?" (p. 69). Se a atual crise sanitária global expõe e amplia os conflitos de classe, quem protege os trabalhadores na fronteira dessa guerra? Ainda tomando por base essa "guerra social", verifıcam-se inúmeras violações de direitos sociais ${ }^{10}$ no Brasil, onde o capital (e sua estrutura de classes essencialmente marcada pelos elementos racial, patriarcal e colonial) amplia, com a pandemia, sua capacidade de destruição de vidas e demonstra sua perversidade diante da morte de trabalhadores, seguindo na busca desenfreada de lucro.

Buscando-se verificar os efeitos da pandemia global na vida dos trabalhadores pobres, em face da desigualdade socioterritorial seja na escala da periferia urbana, seja na escala regional, foram realizados, para fins deste estudo, dois levantamentos. O primeiro cruzou dados 
referentes à proporção de domicílios em aglomerados subnormais ${ }^{11}$ nas capitais brasileiras versus óbitos por 100 mil habitantes decorrentes da Covid-19 (Gráfico 4). A análise desses dados permite observar uma clara correlação entre os dois indicadores, podendo-se inferir que os locais de reprodução social da classe trabalhadora (denominados favelas, comunidades, baixadas etc.) são uma importante determinação da contaminação e da morte pela doença, em decorrência da forçosa aglomeração, na contramão do necessário isolamento social, e dos cuidados gerais com a saúde.

Gráfico 4 - Capitais brasileiras: proporção de domicílios em aglomerados subnormais* versus óbitos por cem mil habitantes por Covid-19

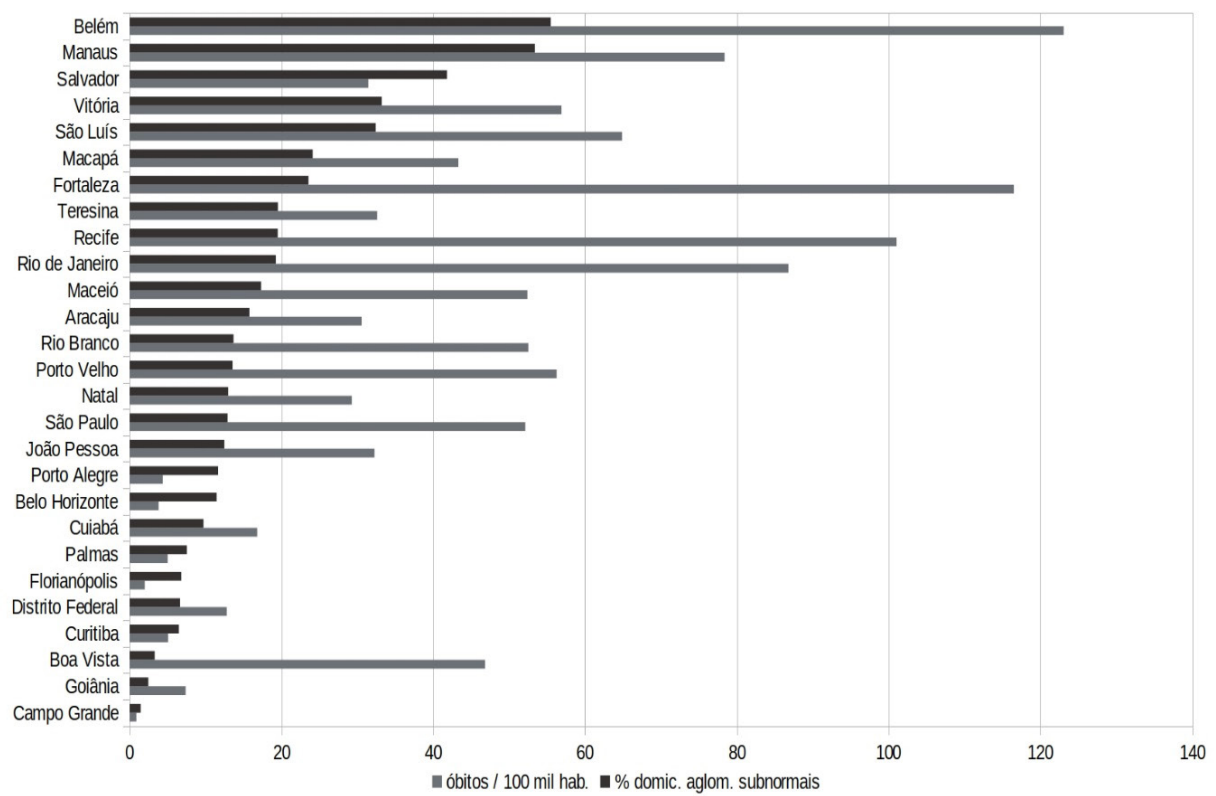

Fonte: Elaborado pelos(as) autores(as) com base em IBGE, 2020 e BRASIL.IO, 2020.

(*) Proporção de domicílios em aglomerados subnormais em relação ao total de domicílios. Dados preliminares de 2019.

Obs.: As capitais foram ordenadas de forma decrescente pela proporção de domicílios em aglomerados subnormais.

Ao tratar das orientações da OMS para frear a pandemia, Maricato (2020) afırma que parte da população brasileira não tem condições de atender a orientação "fique em casa". 
Por que que uma parte da população não pode fazer o isolamento social? Porque ganha no dia para comer no dia seguinte; (...) porque tem mais de três pessoas por dormitório, (...) porque tem cômodo sem ventilação e sem insolação, insalubre, casa sem banheiro. Tem gente que não tem banheiro e não tem água (...). Então, essas autoridades não conhecem a realidade brasileira; elas não sabem como é que são as cidades; elas não sabem como é que o povo vive. (....) o Estado, ele não chega nesses bairros, ele não chega nas periferias. (...) Ninguém vai resolver o problema da pandemia, da moradia sem que você tenha parceria com as lideranças incriveis que nós temos nos bairros de todas as nossas cidades (s. p).

Diante de tais condições, cumpre não reforçar o estigma de que os espaços de moradia da classe trabalhadora são vetores de disseminação do vírus. O que se dá é que a classe trabalhadora sofre os impactos da pandemia, devido à grande desigualdade no acesso aos serviços urbanos. Deve, portanto, constituir uma forma de luta constante, o direito à cidade ${ }^{12}$.

Os dados apresentados no Gráfico 4 apontam ainda que as capitais brasileiras com maiores índices de morte por cem mil habitantes, predominantemente, estão nas regiões Norte e Nordeste, coincidindo com os dados do IBCE (2019) em que essas duas regiões concentram os piores índices de acesso aos serviços de saneamento, fato agravado ainda na Região Norte, onde a ausência de oferta de esgotamento sanitário chega a 79,3\% de domicílios (Gráfico 5). 
Gráfico 5 - Proporção da população residindo em domicílios com ausência de serviços de saneamento, por Grandes Regiões, segundo o tipo de serviço - 2018

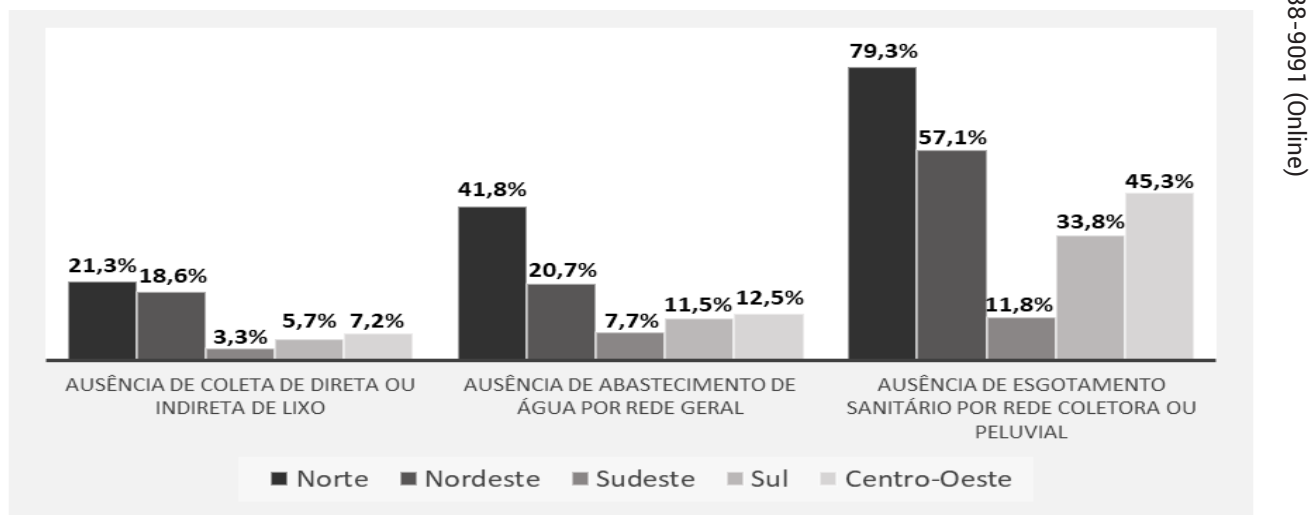

Fonte: IBGE, Pesquisa Nacional por Amostra de Domicílios Contínua 2018, apud IBGE, 2019, p. 68. Nota: Dados consolidados de primeiras entrevistas.

O segundo levantamento ${ }^{13}$ realizado trata do indicador número de óbitos por cem mil habitantes no Brasil nos municípios brasileiros, tendo em vista a necessidade de discutir os dados referentes ao impacto da pandemia conforme as regiões do país. O Mapa 1 revela que, no dia da captura de dados (22 de junho de 2020), as Regiões Norte e Nordeste possuem os maiores índices de morte dessa natureza, sendo mais agravados na Região Norte, o que expressa a enorme desigualdade socioterritorial no Brasil. 


\section{CASOS DE COVID-19 NO BRASIL}

Número de óbitos/100.000 habitantes - 22 de junho de 2020

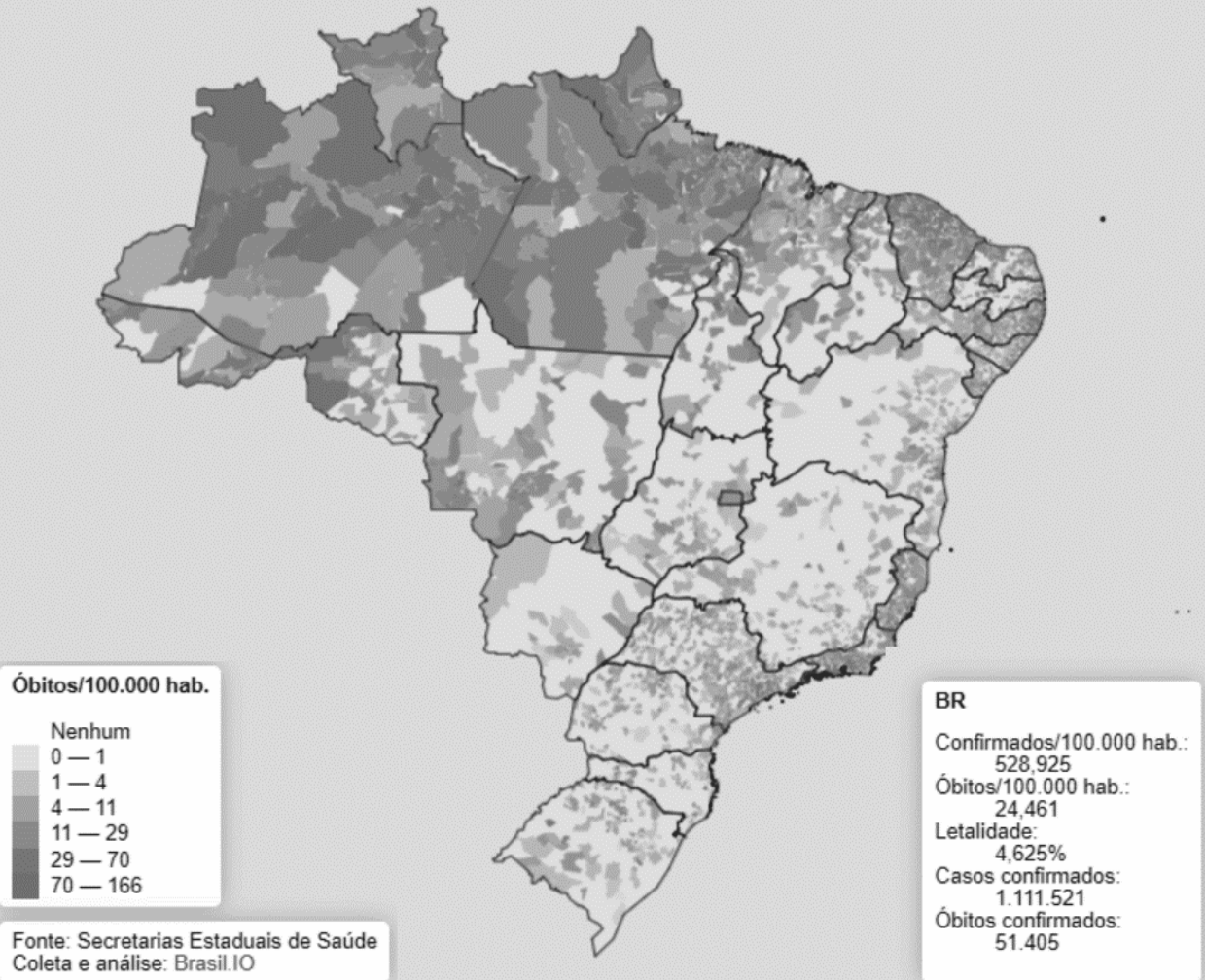

Fonte: elaborado pelos autores ${ }^{14}$ a partir de dados disponíveis em Brasil.io, 2020.

(*) Dados de 22 de junho de 2020.

O estudo feito por pesquisadores da Universidade Federal de Pelotas (EPICOVID19BR ${ }^{15}$ ), divulgado em 25 de maio de 2020 apresentou dados referentes ao teste do Covid-19 em 133 cidades do Brasil e identificou importantes discrepâncias regionais: dentre as 15 cidades com maior incidência da contaminação, 11 são territorializadas na Região Norte, vindo em seguida as regiões Nordeste (Fortaleza e Recife) e Sudeste (Rio de Janeiro e São Paulo). Um dos pesquisadores desse estudo afirma que os casos de Covid-19 em certas cidades do interior da Região Norte podem estar vinculados ao tempo que as pesso- 
as permanecem aglomeradas nas viagens de barco e às dificuldades de acesso aos serviços públicos de saúde ofertados nessas cidades (HORTA, 2020), piores que a média nacional.

O resultado do estudo aludido demonstra como a pandemia impacta - além dos moradores das periferias urbanas - as regiões mais pobres do Brasil, como é o caso da Região Norte, que possui frágil oferta de serviços públicos ${ }^{16}$, o que agrava as possibilidades de condições de contaminação e morte dos moradores das pequenas cidades e dos povos e comunidades tradicionais (ribeirinhos, quilombolas e indígenas).

Diante do abandono do Estado e da desproteção social, nos territórios populares, várias lideranças sociais vêm organizando redes de proteção e solidariedade para doações de alimentos, produtos de limpeza e disponibilização de informações aos moradores. Realizam coleta de recursos para ajudar os trabalhadores desempregados e cuidam dos idosos. Além disso, o Movimento dos Trabalhadores sem Teto/MTST e o Movimento dos Trabalhadores Rurais Sem Terra/MST tem realizado atividades de apoio às famílias como doação de alimentos. Várias entidades de movimentos populares elaboraram 20 propostas contra a pandemia de Covid-19, entre as quais se encontra o fim de todos os despejos e remoções na cidade e no campo e a suspensão do pagamento das prestações dos imóveis adquiridos pelo programa Minha Casa, Minha Vida, durante a pandemia.

Santo Amore, Seemann e Leitão (2020) afırmam que enquanto o governo federal age lentamente para garantir o auxílio emergencial de $\mathrm{R} \$ 600,00$ aos brasileiros mais pobres, ocorrem em todo o país várias ações assistenciais de emergência nos bairros populares, para proteção social dos moradores, a exemplo dos complexos de favelas em São Paulo e Rio de Janeiro.

Essas redes de movimentos se adiantam às ações estatais e renovam a importância da solidariedade de classe que vai permitir que o povo mais pobre e marginalizado sobreviva nessa crise. Uma solidariedade que revela, por outro lado, a perversidade de uma socie- 
dade que delega a lideranças comunitárias o papel de fazer frente ao vírus, dar orientações para prevenção e encaminhar moradores para tratamento ou internação, distribuir alimentos e produtos de higiene. (SANTO AMORE, SEEMANN e LEITÃO, 2020, p. 3)

As lideranças de vários movimentos sociais no Brasil têm feito o que o Estado não faz: criam várias estratégias de ação política em defesa da vida. Ademais, os profissionais de saúde, onde se incluem os assistentes sociais, demonstraram a importância de sua área profissional nos espaços públicos e demonstraram por sua vez, a imperiosa necessidade da defesa universal do Sistema Único de Saúde (SUS) e do Sistema Único de Assistência Social (SUAS).

\section{Considerações Finais}

O ataque à classe trabalhadora, que já ocorria antes da crise sanitária, se agudiza agora com o descaso em relação à vida, em especial a dos trabalhadores pobres, a maioria negros, os quais, somando-se a todas as perdas de direitos, agora perdem o direito de respirar: não há aparelhos respiradores suficientes nos hospitais públicos; e acresce que durante a pandemia, a polícia intensificou o assassinato de jovens pretos e pobres moradores das periferias no Brasil.

A crise sanitária desnudou a perversa desigualdade estrutural do modo de produção capitalista e, paradoxalmente, favorece ganhos exorbitantes da fração dominante do capital financeiro; demonstrou como as políticas de orientação neoliberal vêm promovendo uma altíssima exploração da força de trabalho, principalmente dos países periféricos, através da degradação de direitos socais e trabalhistas e privatizações dos serviços públicos.

No Brasil, as condições de vida dos trabalhadores, já agravadas pelo histórico de crise econômica, desconstrução da frágil democracia e avanço das políticas ultraliberais do Presidente Jair Bolsonaro, pioram fortemente com a pandemia, onde um governo desqualificado demonstra um absoluto desrespeito pela vida. 
Ademais, a crise sanitária também exacerbou a estrutural desigualdade social, racial e de gênero no país, somadas às desigualdades socioterritoriais que expressam a estrutura fundiária (com forte acento no capital imobiliário) que historicamente permite que os pobres ocupem os piores lugares, desprovidos de infraestrutura urbana.

Os crescentes índices de contaminação da Covid-19 nas regiões Nordeste e Norte são a expressão de várias formas de segregação e desigualdade socioterritorial no Brasil e revelam as disparidades no acesso aos serviços públicos no país e, especialmente no caso do Norte, fragilizam a vida de moradores de pequenas cidades, indígenas, quilombolas e ribeirinhos.

Nos processos contraditórios, a pandemia também demonstrou a força das organizações comunitárias em todo o país. Diante do abandono do Estado, lideranças protagonizam inúmeras formas de organização para salvar vidas. Por sua vez, as instituições de pesquisa, tão atacadas pelo Governo Federal, mostram sua força e importância. Enquanto o governo subnotificava os números de contaminados e mortos, as universidades e centros de pesquisa trouxeram os dados a público, além das investigações sobre a vacina e possíveis tratamentos para a doença. Também é digno de nota o papel dos profissionais de saúde (médicos, enfermeiros e assistentes sociais), que atuaram fortemente em favor da vida, demonstrando a imperiosa necessidade de defesa dos serviços públicos gratuitos e de qualidade.

As instituições de ensino e pesquisa têm uma dupla tarefa: lutar pela sua própria existência, voltada ao interesse público, e se aproximar cada vez mais da realidade brasileira, com articulação com as lideranças sociais que lidam no cotidiano com as inúmeras carências. Redobra-se a necessidade das lutas políticas em defesa da vida. A pandemia global demonstrou que o capitalismo está em colapso econômico e moral, e que precisa ser superado urgentemente. 


\section{Referências}

BRASIL.IO. Especial COVID-19 - Dados por Município. Disponivel em: https://brasil.io/covid19/. Acesso em: 18 jun. 2020.

CARDOSO, Adauto Lúcio; ARAÚJO, Rosane Lopes de; GHILARDI Flávio Henrique. Necessidades Habitacionais. In: Planos Locais de Habitação de Interesse Social: Curso à Distância. Aula 4. Brasília, DF: Ministério das Cidades. Secretaria Nacional de Habitação, [2009]. Disponível em: http://planodiretor. mprs.mp.br/arquivos/planoslocais.pdf. Acesso em: 23 jun. 2020.

COELHO, Flavio C. et al. Assessing the potential impact of COVID-19 in Brazil: Mobility, Morbidity and the burden on the Health Care System. MedRxiv. March, 2020. doi: https://doi.org/10.1101/2020.03.19.20039131. Disponível em: https://www.medrxiv.org/content/10.1101/2020.03.19.20039131v2. Acesso em: 19 jun. 2020.

DE LA FUENTE, Francisco J. A dura realidade da saúde pública no Chile: 'Se você não tem dinheiro, morre'. BBC News Mundo. Disponível em: https://www.bbc.com/portuguese/internacional-50494429. Acesso em: 26 jun. 2020.

ENGELS, Friedrich. A situação da classe trabalhadora na Inglaterra. Tradução B.A. Schumann; edição José Paulo Netto. São Paulo: Boitempo, 2008.

EPICOVID19BR.- Universidade Federal de Pelotas. Disponível em: https:// wp.ufpel.edu.br/covid19/files/2020/05/EPICOVID19BR-release-fase-1-Portugues.pdf. Acesso em: 25 jun. 2020.

GOMES, Helder. Introdução. In: GOMES, Helder (Org.). Especulação e lucros fictícios: Formas parasitárias da acumulação contemporânea. São Paulo: Outras Expressões, 2015.

HARVEY, David. 17 Contradições e o fim do capitalismo. São Paulo, SP: Boitempo, 2016.

HARVEY, David. Política anticapitalista em tempos de COVID-19. In: DAVIS, Mike, et al: Coronavírus e a luta de classes. Terra sem Amos: Brasil, 2020.

HERRERA, Rémy. O Capital fictício no centro da crise (Prefácio). In: COMES, Helder (Org.). Especulação e lucros fictícios: Formas parasitárias da acumulação contemporânea. São Paulo: Outras Expressões, 2015.

HOBSBAWN, Eric. Era dos Extremos: O breve século XX - 1914-1991. São Paulo: Companhia das Letras, 1995. 
HORTA, Bernardo Lessa. A interiorização da Covid-19. [Vídeo/Live]. FASE/ Amazônia. Disponivel em: https://www.youtube.com/watch?v=sKiHzwb8azs. Acesso em 17 jun. 2020.

IBCE. Síntese de indicadores sociais: uma análise das condições de vida da população brasileira: 2019 / IBGE, Coordenação de População e Indicadores Sociais. - Rio de Janeiro: IBCE, 2019.

IBGE. Aglomerados Subnormais. 2020. Disponivel em: https://www. ibge.gov.br/geociencias/organizacao-do-territorio/tipologias-do-territorio/15788-aglomerados-subnormais.html?=\&t=acesso-ao-produto\&utm source=covid19\&utm_medium=hotsite\&utm_campaign=covid_19. Acesso em: 19 jun. 2020.

INDEXMUNDI. Produto Interno Bruto (PIB) per capita - América do Sul. Disponível em: https://www.indexmundi.com/map/?v=67\&r=sa\&l=pt. Acesso em 26 jun. 2020.

LARA, Ricardo. Pandemia e capital: as repercussões da Covid-19 na reprodução social. Revista Libertas, Juiz de Fora, v.20, n.1, p. 53-69, jan. / jun. 2020.

LENIN, V. I. Imperialismo, estágio superior do capitalismo: ensaio popular - 1. ed. - São Paulo: Expressão popular, 2012.

LOLE, Ana; ALMEIDA, Carla Cristina Lima de; STAMPA, Inez; COMES, Rodrigo Lima Ribeiro. Crise e pandemia da COVID-19 - leituras interseccionais. In (Orgs.) Para além da quarentena: reflexões sobre crise e pandemia. Rio de Janeiro: Mórula Editorial, 2020.

MARICATO, Erminia. Meia Hora com o BrCidades. [Vídeo/Live] 1 de junho de 2020. Disponivel em: https://www.facebook.com/brcidades/videos/247770382959124/. Acesso em: 14 jun. 2020.

MARX, Karl. ENGELS, Friedrich. Manifesto comunista. São Paulo: Boitempo. 2010. MARX, Karl. O Capital - Crítica da economia política - Livro 1, Volume II. 14. ed. Rio de Janeiro: Editora Bertrand Brasil S. A, 1994.

NETTO, José Paulo. Introdução ao estudo do método em Marx. São Paulo: Expressão Popular. 2011.

PAULANI, Leda Maria. A crise do regime de acumulação com dominância da valorização financeira e a situação do Brasil. Estudos Avançados, v. 23, n. 66, p. 25-39, 2009. 
SANTANA, Joana Valente. Pequenas cidades na Amazônia: desigualdade e seletividade no investimento da infraestrutura habitacional. In: Joana Valente Santana; Anna Carolina Gomes Holanda; Aldebaran do Socorro Farias de Moura. (Org.). A questão da habitação em municípios Periurbanos na Amazônia. 1ed. Belém: Editora da Universidade Federal do Pará - Edufpa, 2012, v., p. 77-96. SANTO AMORE, Caio; SEEMANN, Heitor; LEITÃO, Karina. Saúde pública e moradia popular: Áreas de contato entre campos do conhecimento e ação. DILEMAS: Revista de Estudos de Conflito e Controle Social - Rio de Janeiro Reflexões na Pandemia, p. 1-19, 2020.

UNIVERSIDADE JOHNS HOPKINS, Evolução nos casos do novo coronavírus. Jornal Folha de São Paulo. Disponivel em: https://arte.folha.uol.com.br/ equilibrioesaude/2020/evolucao-nos-casos-do-novo-coronavirus/. Acesso em: 22 jun. 2020.

\section{Notas}

1 Doutora em Serviço Social pela UFRJ. Professora Associada da Faculdade e do Programa de Pós-graduação em Serviço Social da Universidade Federal do Pará (UFPA). Brasil. Orcid: https://orcid.org/0000-0003-4033-1317. Bolsa produtividade em pesquisa do CNPq. E-mail: joanavalente@ufpa.br/joanavalentesantana@gmail.com.

2 Doutor em Engenharia de Sistemas e Computação pela UFRJ. Professor Titular da Faculdade de Computação e do Programa de Pós-graduação em Educação da Universidade Federal do Pará (UFPA). Brasil. Orcid: http://orcid.org/0000-00031949-5077. E-mail: ferreira@ufpa.br.

3 Sumariamente, enquanto todo capital individual já é, por si, uma concentração, que aumenta na medida do aumento da massa de riqueza que funciona como capital, a centralização ocorre quando muitos capitais se fundem em um só (MARX, 1994, p. 726 e seg.).

4 Em tempos de difusão significativa do relativismo pós-moderno, contestando a objetividade e a possibilidade da verdade, cabe asseverar, com Netto (2011, p. 23), que "a teoria tem uma instância de verificação de sua verdade, instância que é a prática social e histórica".

5 Lênin analisa os dados das grandes empresas na Alemanha e Estados Unidos na primeira década do Século XX. Vale destacar que na Alemanha, em 1907, se o número de grandes empresas correspondia a 0,9\% do total, elas empregavam, entretanto, 39,4\% dos operários, respondiam por uma produção de $39,4 \%$ do total e empregavam mais de três quartos da energia consumida no país. Fenô- 
meno similar, de forte avanço da centralização de capital nas décadas anteriores, acontecia nos Estados Unidos.

6 Considera-se aqui que a comparação adequada entre países deve ser feita considerando-se não uma determinada data, mas o número de dias decorridos desde o início da pandemia. Assim, por exemplo, o $100^{\circ}$ dia de pandemia para dois países pode ocorrer em datas distintas.

7 Estes e os próximos dados de Produto Interno Bruto (PIB) per capita foram retirados de (INDEXMUNDI, 2020).

8 Com base nos dados da Fundação João Pinheiro (2005), Cardoso, Araújo e Chilard (2009) consideram os domicílios inadequados os que possuem carências de infraestrutura, adensamento excessivo de moradores, problemas de natureza fundiária, em alto grau de depreciação ou sem unidade sanitária domiciliar exclusiva.

9 "Taxa de conversão da paridade de poder de compra para consumo privado, R\$ 1,66 para US\$ 1,00 PPC 2011, valores diários tornados mensais e inflacionados pelo IPCA para anos recentes" (IBCE, 2019, p. 63).

10 São exemplos da violação de direitos no Brasil: a) o racismo aberto e o crescimento dos assassinatos de pessoas negras, a maioria jovens; b) a desigualdade de gênero: as mulheres precisam se isolar com o seu agressor aumentando os casos de violência doméstica, além de cuidar da casa e da família, incluindo o cuidado com os doentes acometidos pela COVID-19; c) a falta de hospitais públicos para atendimento dos casos de infecção, com alto grau de falecimento das pessoas idosas; d) nos territórios populares, os moradores estão à própria sorte e sem a proteção do estado, sendo controlados pela milícia e pelo tráfico de drogas.

11 "Os aglomerados subnormais são formas de ocupação irregular em áreas urbanas, para fins de habitação, de terrenos de propriedade alheia (públicos ou privados). Em geral, são caracterizados por um padrão urbanístico irregular, carência de serviços públicos essenciais e localização em áreas com restrição a ocupação. Em alguns Municípios, são conhecidos como favelas, comunidades, grotas, palafitas, invasões, ressacas e outras nomenclaturas" (IBCE, 2020, s.p.). Vale ressaltar que os dados do IBCE são considerados genéricos e não expressam as particularidades e diferenciações do espaço de moradia da classe trabalhadora no Brasil. De todo modo, as pesquisas do IBCE e os dados disponíveis são ferramentas importantíssimas de pesquisa e devem ser fortemente valorizados neste momento de desqualificação da ciência no Brasil.

12 Em coletânea de textos com análises sobre a pandemia Lole, Almeida, Stampa e Comes (2020, p. 10) afirmam que: "Na memória do eugenismo e higienismo o cuidado se reatualiza como controle, anulação, tal como se expressa em narrativas como fique em casa, higienize mãos e ambientes, alimente-se sauda- 
velmente. Recomendações alheias às vidas nas periferias e favelas, à interdição do trabalho digno em nome de ajustes fiscais, às vidas que pulsam nas ruas, prisões, aldeias, quilombos. Ou ainda, humilhação e desespero, ao lançar multidões aglomeradas a filas de fome e de angústia por um auxílio emergencial, atiradas à sua própria sorte, ao desgoverno".

13 Levantamento realizado com base nos dados disponíveis em Brasil.io (2020).

14 Com a colaboração do Arquiteto e Urbanista Rogério Santana Maués.

15 Estudo coordenado pelo Centro de Pesquisas Epidemiológicas da Universidade Federal de Pelotas, financiado pelo Ministério da Saúde. (EPICOVID19BR, 2020).

16 O estudo de Santana (2012) discute a desigualdade e seletividade no investimento da infraestrutura habitacional em pequenas cidades na Amazônia, demonstrando a enorme precariedade das condições habitacionais de pequenas cidades no estado do Pará com destaque para a carência no acesso à água, esgotamento sanitário e coleta de lixo, além da alta incidência de domicílios rústicos (casas construídas com material improvisado e inadequado). 